\title{
Study of Numerical Analysis on Smoke Exhaust Performance of Portable Smoke Exhaust Fan
}

\author{
Jung-Yup Kim \\ Multi Disaster Countermeasures Organization, Korea Institute of Civil Engineering and Building Technology, Goyang, Korea \\ Email: jykim1@kict.re.kr
}

How to cite this paper: Kim, J.-Y. (2017) Study of Numerical Analysis on Smoke Exhaust Performance of Portable Smoke Exhaust Fan. Open Journal of Fluid Dynamics, 7, 205-218. https://doi.org/10.4236/ojfd.2017.72014

Received: April 18, 2017

Accepted: June 6, 2017

Published: June 9, 2017

Copyright (c) 2017 by author and Scientific Research Publishing Inc. This work is licensed under the Creative Commons Attribution International License (CC BY 4.0).

http://creativecommons.org/licenses/by/4.0/

\section{(c) (i) Open Access}

\begin{abstract}
In houses and general buildings of environment where smoke control equipment is not installed, or its operation is difficult, there is a need to develop and utilize a portable smoke exhaust fan that can perform emergency ventilation in case of fire suppression and rescue operations. As a part of the development process for portable smoke exhaust fans, a numerical analysis model of the portable smoke exhaust fan was derived from the building in which a fire occurred, and an analysis on the smoke and toxic gas exhaust effects was performed in this study. The numerical analysis results showed that under a condition where the height of an opening is less than $1.0 \mathrm{~m}$ after fire source disappears in a situation where the smoke exhaust fan does not operate, smoke does not come out well, and thus the density of smoke within the target area does not drop significantly. On the other hand, if the smoke exhaust fan operates after the fire source disappears, smoke is directly exhausted to the outside due to the operation of the smoke exhaust fan, and the smoke density within the space drops sharply in all opening height conditions, thereby getting close to zero.
\end{abstract}

\section{Keywords}

Smoke Exhaust; Portable Fan, Smoke Density, CO Density, Numerical Analysis

\section{Introduction}

Results of a research show that more than $70 \%$ of casualties in the event of a fire accident are caused by smoke [1], thus the importance of smoke control equipment to cope with smoke which is a major obstacle to fire-fighting activities has been highlighted. Especially in the event of a fire in houses and general buildings where smoke control equipment is not installed, there is a need for a portable smoke control system for efficiently discharging smoke in the buildings in order 
to efficiently perform fire suppression operations and ensure the safety of firefighters. According to some assessments, the pressurization fans of air supply type which are currently used in fire departments have a limitation in discharging smoke quickly in the space for staging fire suppression operations inside the building. Meanwhile, smoke generated in case of a fire can maintain a considerably high temperature inside the building. In this case, if the airflow is formed by air supplied by the pressurization fan from the outside, there is a high possibility of causing heat damages to the firefighters performing fire suppression and rescue operations.

Therefore, it is considered that the utilization of portable smoke exhaust fans that can perform emergency ventilation in the case of fire suppression and rescue operations in houses and general buildings of environment where smoke control equipment is not installed, or its operation is difficult will not only enhance the safety of firefighters during the operations but also prevent job-related firefighter injuries and casualties.

In Korea, there are no detailed national standards for the production and operation of smoke exhaust blowers for buildings, and related standards are presented briefly in Fire Safety Standard for Smoke Control System (NFSC501), which says that the motor and blower sections of the smoke exhaust blower shall be installed separately, and the blower section shall be subjected to an effective heat treatment [2]. Meanwhile, the related industry has been manufacturing smoke exhaust blowers and evaluating their performance according to its own standards and thus failed to secure effective and reliable performance data, and technology developments for improving the performance of smoke exhaust blowers have not yet been achieved. Therefore, it is necessary to conduct research and development of related fields in order to design and operate smoke ventilation systems considering the use of buildings and fire risks and improve domestic technologies for smoke exhaust blowers which are economical and reliable.

In other countries, the European standard EN 12101-3 and U.S. ANSI/ ASHRAE standard 149 present detailed design and performance test standards for smoke exhaust blowers [3] [4], and studies have been conducted regarding the impact of these standards and future improvement directions [5]. Meanwhile, a research on the smoke exhaust systems for the smoke emission in the event of a fire in the building has been underway. In particular, an impact of the exhaust speed and the height of exhaust opening in a mechanical smoke exhaust system on the smoke exhaust performance has been investigated [6] [7] [8].

In this study, a numerical analysis model of the portable smoke exhaust fan was derived from the building in which a fire occurred, and an analysis on the smoke and toxic gas exhaust effects was performed as a part of the development process for the portable exhaust fan that can perform emergency ventilation in the case of fire suppression and rescue operations. The main purpose of this study was to set up the three-dimensional numerical model and scenario about 
analysis on smoke exhaust performance of portable smoke exhaust fan.

\section{Numerical Analysis Conditions and Methods}

Table 1 shows the development specifications of the portable exhaust fan to be developed in this study. As shown in the table, the design flowrate is 400 CMM, and the blade diameter is $630 \mathrm{~mm}$.

In order to investigate the smoke exhaust effects of the developed portable exhaust fan, a numerical analysis model was set up as shown in Figure 1. As shown in the figure, the size of the analysis target space was $10 \mathrm{~m}$ in length and width, and its height was set to $3 \mathrm{~m}$. The opening was placed at the central point of the left side wall of the space to be analyzed, and the numerical analysis was performed by setting the width of the opening to $2.0 \mathrm{~m}$ and changing the height of the opening from 0.5 to $2.0 \mathrm{~m}$. And an exhaust port was placed at the bottom of the center of the right side wall of the analysis target space to simulate the operation of the smoke exhaust fan. For the exhaust fan operation condition, the air flow rate at the exhaust port was set to $400 \mathrm{CMM}$, and the smoke flow rate at the exhaust port was set to $0 \mathrm{CMM}$ with respect to the condition where the smoke exhaust fan is not installed.

As mentioned above, the numerical analysis was performed by setting conditions according to the operation of the smoke exhaust fan and the change of the opening height as shown in Table 2.

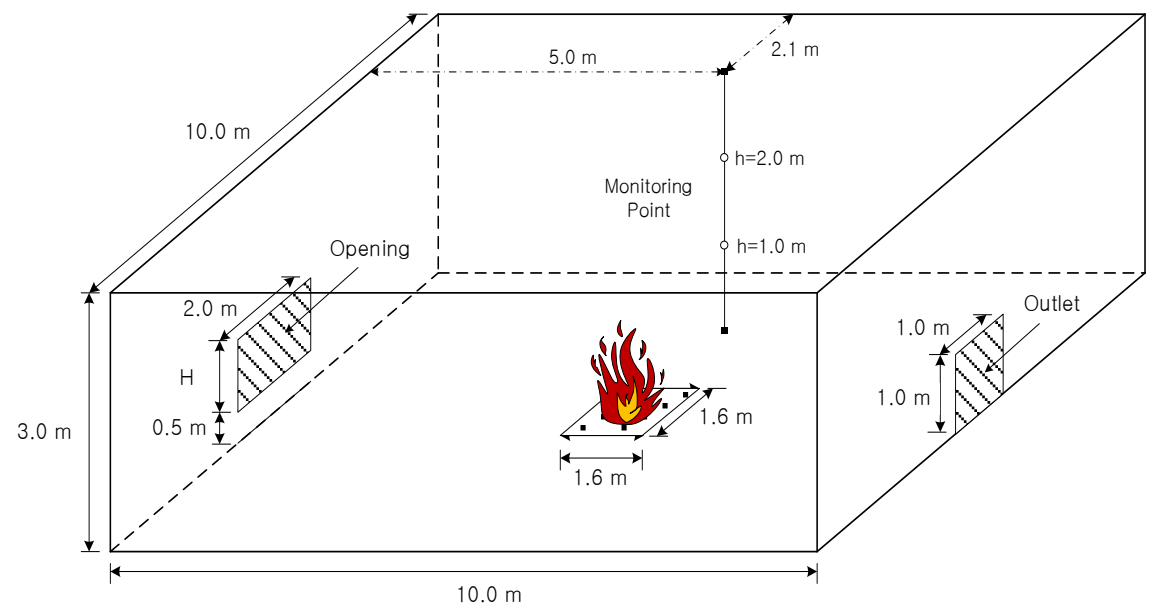

Figure 1. Design plan of analysis model.

Table 1. Development specifications of portable exhaust fan.

\begin{tabular}{cc}
\hline Item & Specification \\
\hline Flowrate & $400 \mathrm{CMM}$ \\
Power & $2.2 \mathrm{~kW}$ \\
Blade diameter & $630 \mathrm{~mm}$ \\
Blade material & Aluminium \\
Size & $700 \times 700 \times 500 \mathrm{~mm}$ \\
\hline
\end{tabular}


Table 2. Conditions of numerical analysis.

\begin{tabular}{ccc}
\hline Case & Height of opening $(\mathrm{m})$ & Operation of exhaust fan \\
\hline Case 1 & 0.5 & Off \\
Case 2 & 1 & Off \\
Case 3 & 1.5 & Off \\
Case 4 & 2 & Off \\
Case 5 & 0.5 & On \\
Case 6 & 1 & On \\
Case 7 & 1.5 & On \\
Case 8 & 2 & On \\
\hline
\end{tabular}

The size of the fire source was set at $1.6 \times 1.6 \mathrm{~m}$ at the center of the bottom of the space to be analyzed. And a fast growth condition with a fire growth coefficient of $0.4689 \mathrm{~kW} / \mathrm{s}^{2}$ was assumed as a heat generation model with time, and $2000 \mathrm{~kW}$ was applied as the maximum heat release rate of steady state. As shown in Figure 2, the heat release rate caused by the fire was set to be maintained at the same value after reaching the maximum heat release rate of $2,000 \mathrm{~kW}$ at 206.5 seconds and set to be zero after the extinction of the fire at 300.0 seconds. This is to investigate the exhaust effects of the smoke exhaust fan on the smoke generated by the fire. Therefore, the operation curve of the smoke exhaust fan with time was set to operate the smoke exhaust fan from 420.0 seconds after the fire disappears as shown in Figure.

Heptane was applied as a combustion material, and the chemical combustion heat was set to $41,200 \mathrm{~kJ} / \mathrm{kg}$, the CO generation rate 0.010 , and the smoke generation rate 0.037 , respectively. Meanwhile, the radiative portion of heat release rate $\left(Q_{R}\right)$ was set to $30 \%$ of the heat release rate.

The numerical analysis was performed using FDS 6.4, a three-dimensional program developed specifically for fire protection-related sectors [9].

Figure 3 shows the numerical analysis model of the analysis target space. There is a fire source at the center of the floor. The opening with $0.5 \mathrm{~m}$ in height is installed on the left side, and the exhaust port which models the smoke exhaust fan is installed on the right side.

\section{Numerical Analysis Results}

Figures 4-15 show the results of the numerical analysis. Figure 4 shows temperature contours on center plane with time for Case 1 where the opening height is $0.5 \mathrm{~m}$, and the smoke exhaust fan does not operate when a fire breaks out. Figure 4(a) shows the temperature contours when 200 seconds pass after a fire occurs. As shown in the figure, the high-temperature plume rises in the fire source located at the center of the bottom, and the temperature of more than $200^{\circ} \mathrm{C}$ is formed around the ceiling. On the other hand, it can be seen that the high-temperature airflow from the ceiling descends along the wall surface and 


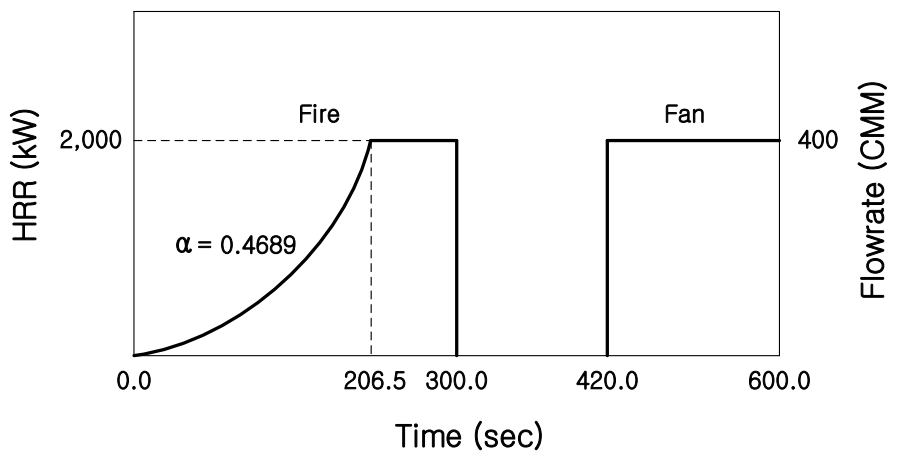

Figure 2. Curves of HRR and Fan operation.

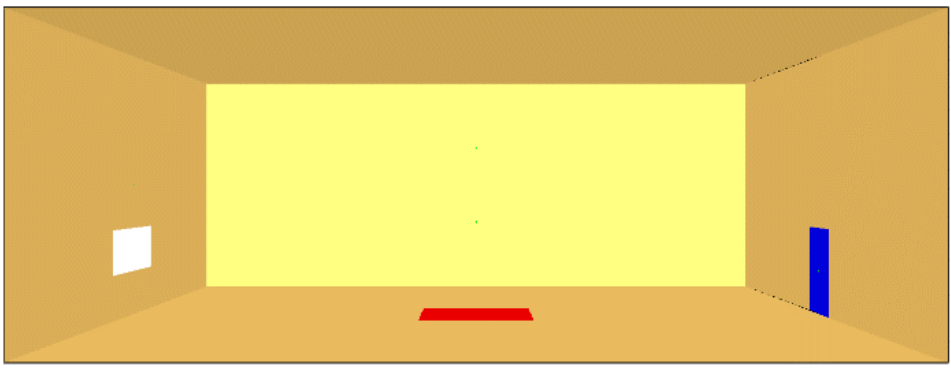

Figure 3. Analysis domain of space.

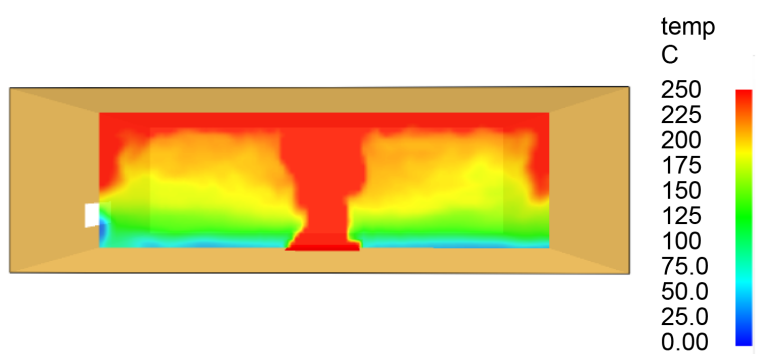

(a)

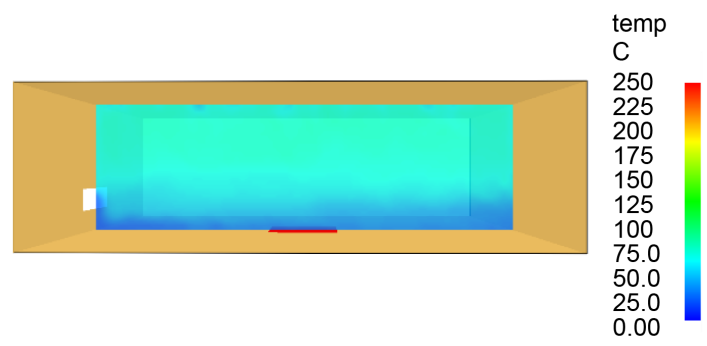

(b)

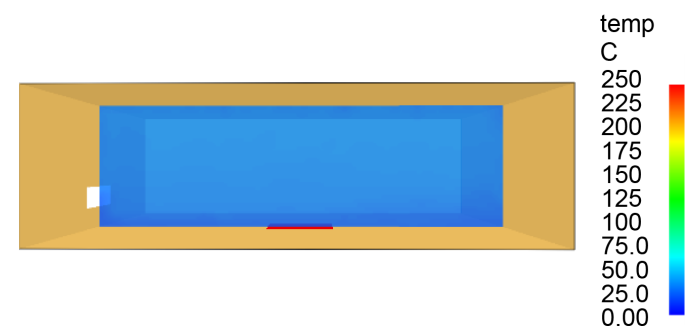

(c)

Figure 4. Temperature contours on center plane with time for Case 1. (a) at $200 \mathrm{~s}$; (b) at $400 \mathrm{~s} ;$ (c) at $600 \mathrm{~s}$. 


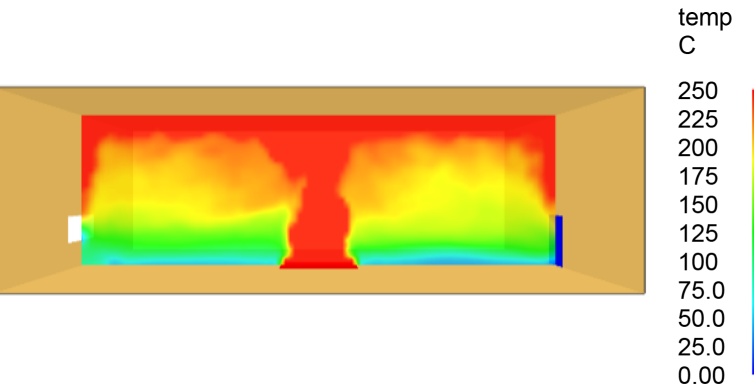

(a)

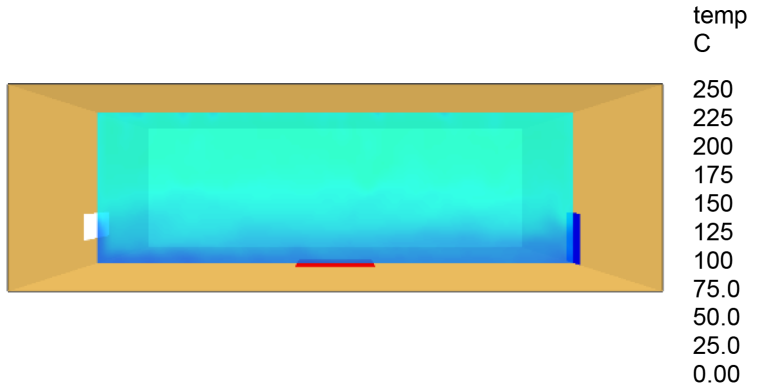

(b)

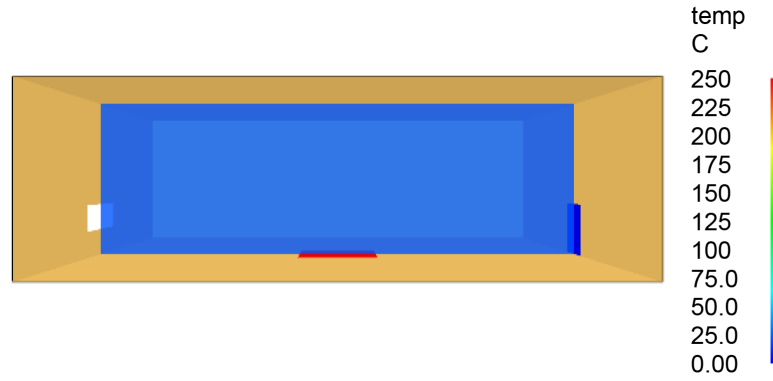

(c)

Figure 5. Temperature contours on center plane with time for Case 5. (a) at $200 \mathrm{~s}$; (b) at $400 \mathrm{~s} ;$ (c) at $600 \mathrm{~s}$.

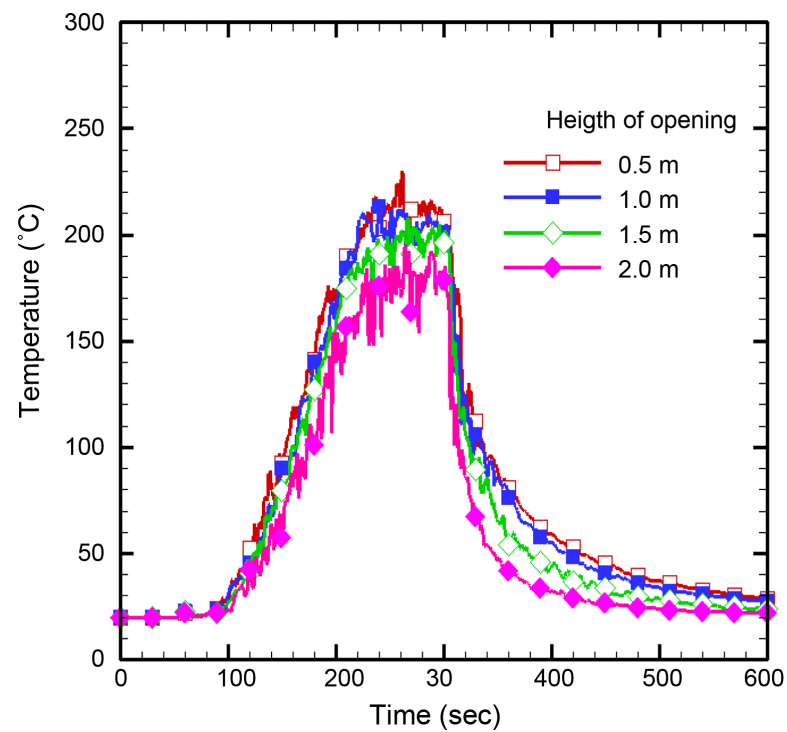

Figure 6. Temperature variations with height of opening for fan-off condition. 


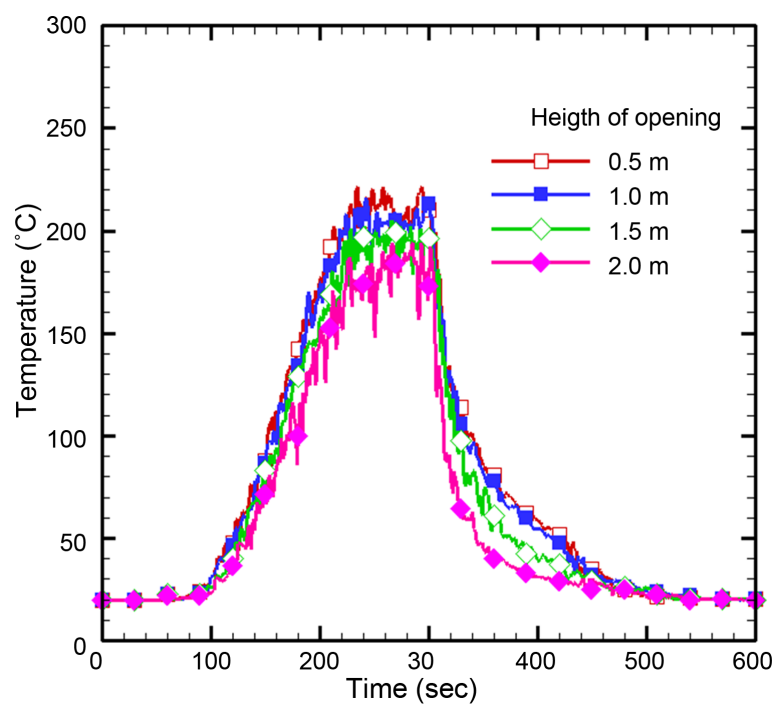

Figure 7. Temperature variations with height of opening for fan-on condition.

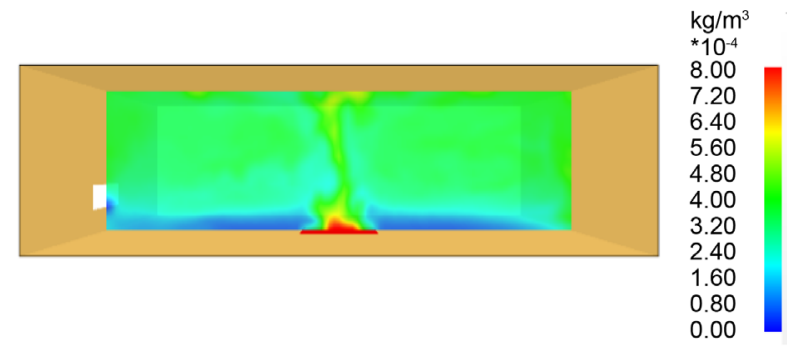

(a)

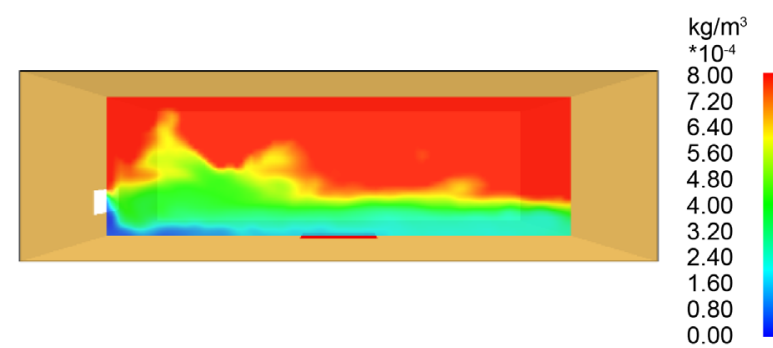

(b)

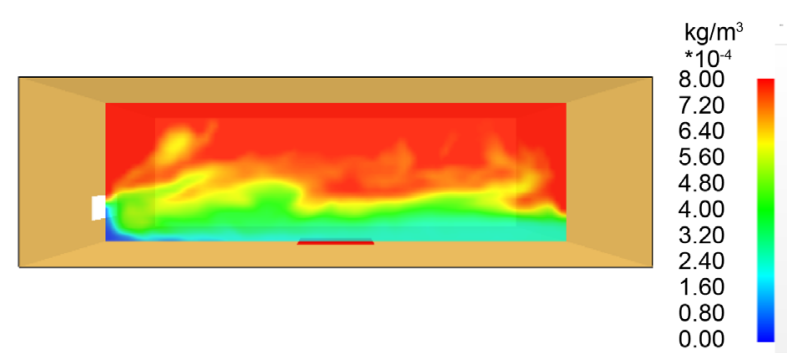

(c)

Figure 8. Smoke density contours on center plane with time for Case 1. (a) at $200 \mathrm{~s}$; (b) at $400 \mathrm{~s} ;$ (c) at $600 \mathrm{~s}$.

flows out to the outside through the opening. Figure 4(b) shows the temperature contours when 400 seconds pass after a fire occurs. That is, it shows a state where 100 seconds pass after the fire disappears in 300 seconds. As shown in the 


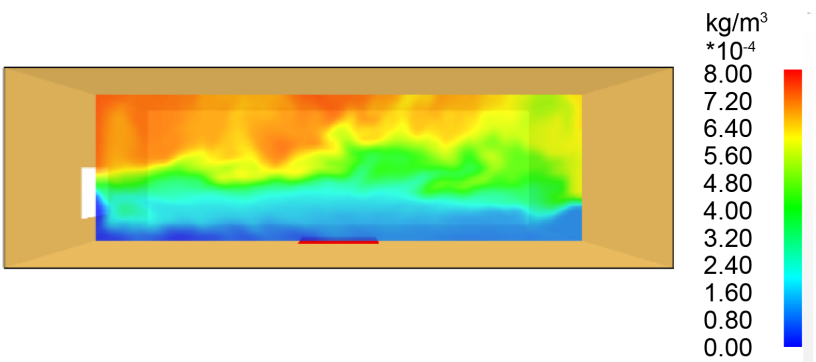

(a)

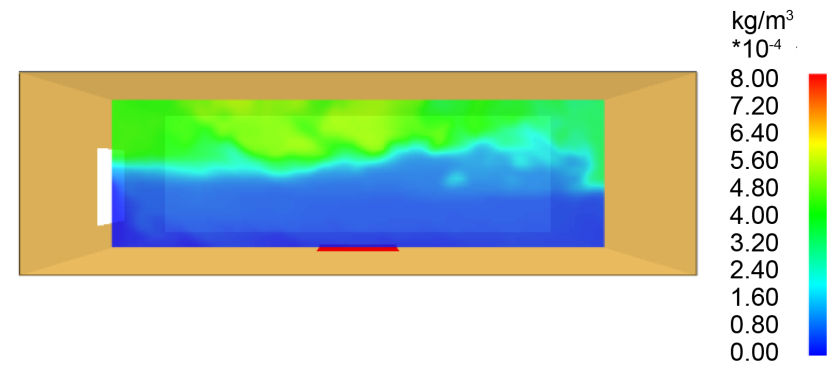

(b)

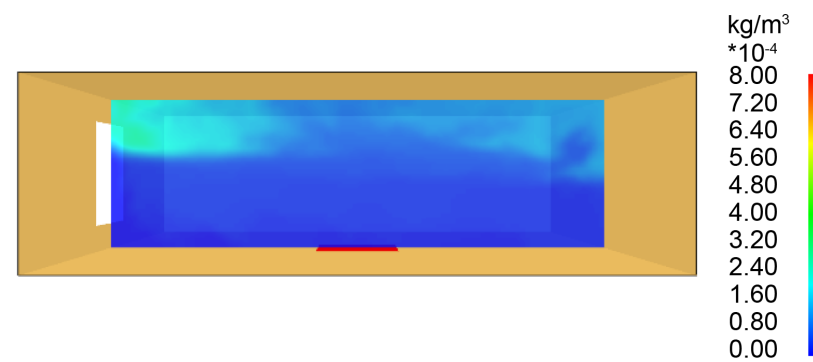

(c)

Figure 9. Smoke density contours on center plane at $600 \mathrm{~s}$ with height of opening for fanoff condition. (a) $1.0 \mathrm{~m}$; (b) $1.5 \mathrm{~m}$; (c) $2.0 \mathrm{~m}$.

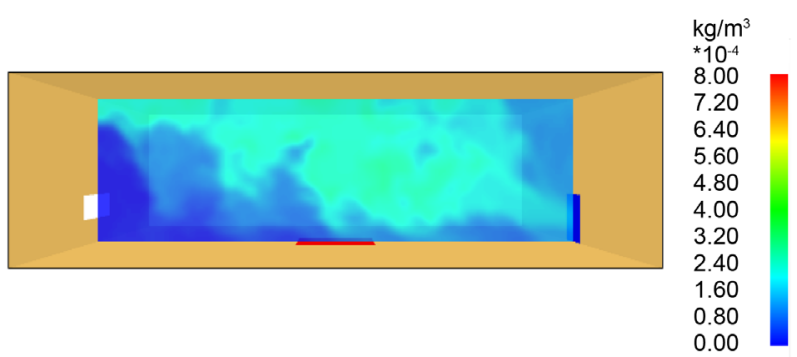

(a)

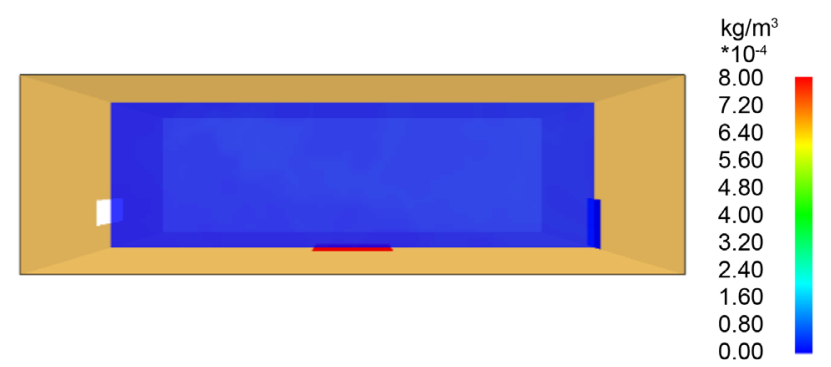

(b)

Figure 10. Smoke density contours on center plane with time for Case 5. (a) at $500 \mathrm{~s}$ (b) at $600 \mathrm{~s}$. 


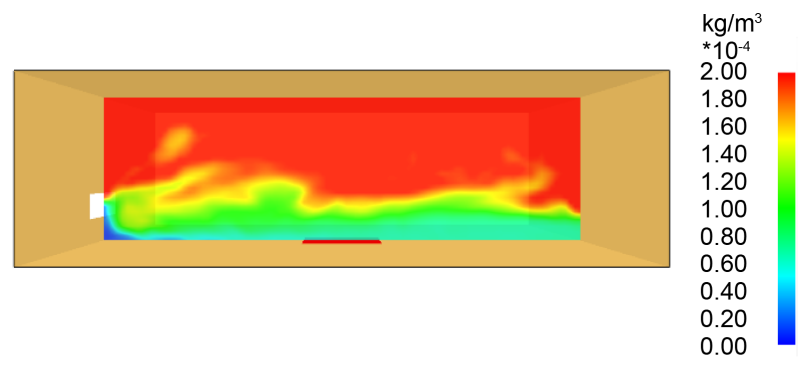

(a)

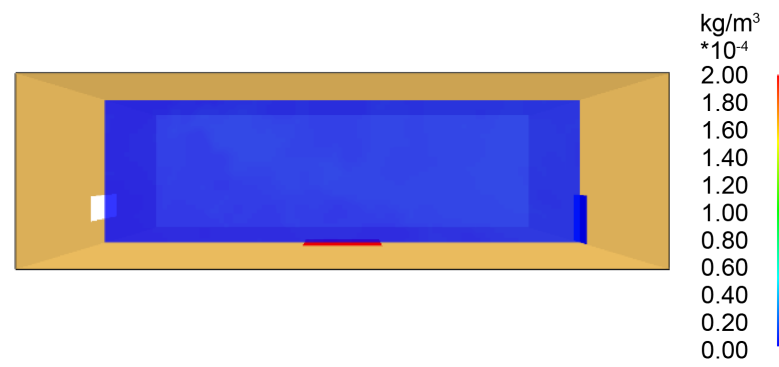

Figure 11. CO density contours on center plane at $600 \mathrm{~s}$ with fan operating condition. (a) Fan-off condition; (b) Fan-on condition.

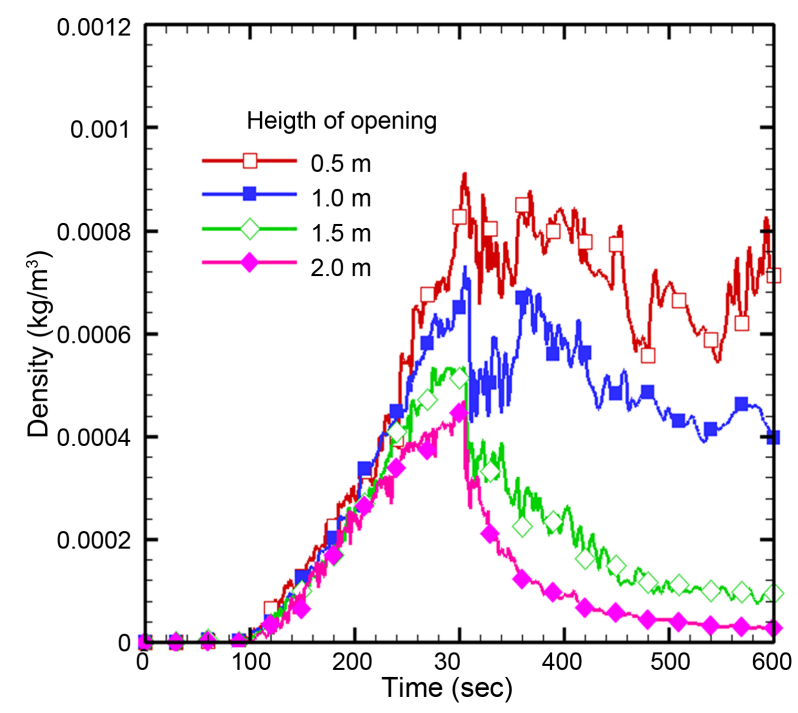

Figure 12. Smoke Density variations with height of opening for fan-off condition.

figure, the temperature of the upper middle part is about $60^{\circ} \mathrm{C}$ as the temperature in the space drops after the fire source disappears. Figure 4 (c) shows the temperature contours when 600 seconds pass after a fire occurs. The temperature in the space is about $30^{\circ} \mathrm{C}$, which is close to the outdoor temperature of $20^{\circ} \mathrm{C}$.

Figure 5 shows temperature contours on center plane with time for Case 5 where the opening height is $0.5 \mathrm{~m}$, and the smoke exhaust fan operates when a fire occurs. Figure 5(a) shows the result similar to Figure 4(a), which is the result of Case 1. This is because Case 1 and Case 5 have the same analysis conditions at 200 seconds. The analysis result of Figure 5 (b) is also similar to that of Figure 4(b), when Case 1 and Case 5 have the same analysis conditions. Mean 


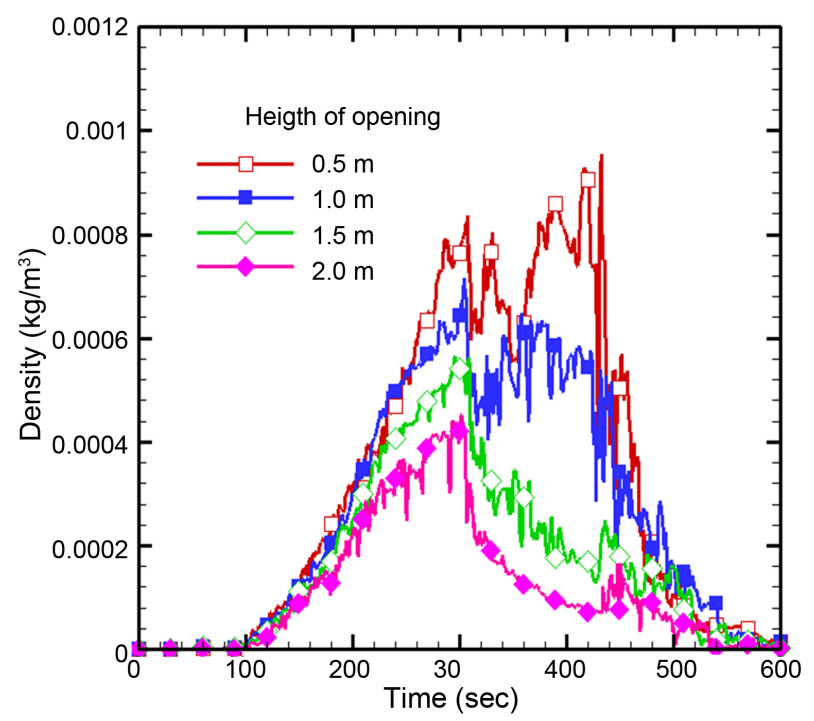

Figure 13. Smoke density variations with height of opening for fan-on condition.

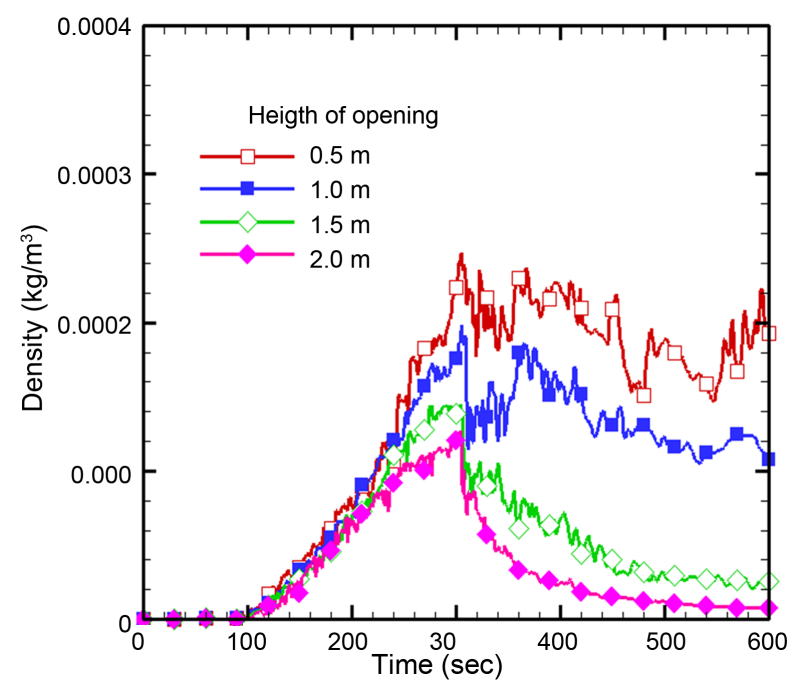

Figure 14. CO density variations with height of opening for fan-off condition.

while, as the smoke exhaust fan starts operating from 420 seconds, and the air in the space is completely discharged, the temperature in the space drops to $20^{\circ} \mathrm{C}$, which is the outdoor temperature as in Figure 5(c).

Figure 6 shows temperature variations over time with height of opening for fan-off condition at the "monitoring point" of $1 \mathrm{~m}$ in the lower part of Figure 1. As shown in the figure, the temperature of the monitoring point rises to more than $200^{\circ} \mathrm{C}$ up to 300 seconds when the fire source is present, and then decreases gradually after the temperature rapidly drops to less than $50^{\circ} \mathrm{C}$ up to about 400 seconds after 300 seconds when the fire source disappears. It can be found that as the height of the opening increases, the temperature at the monitoring point becomes lower, and the temperature in the space is almost close to the outdoor temperature of $20^{\circ} \mathrm{C}$ at 600 seconds at the opening height ranging from 1.5 to $2.0 \mathrm{~m}$. 


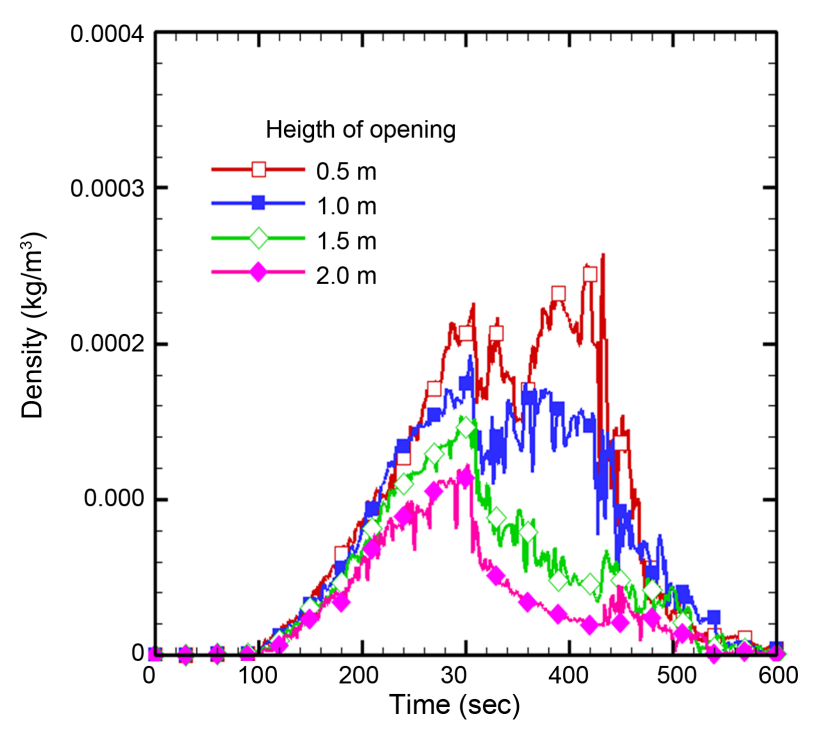

Figure 15. CO density variations with height of opening for fan-on condition.

Figure 7 shows temperature variations over time with height of opening at the monitoring point of $1 \mathrm{~m}$ in the lower part for condition where the smoke exhaust fan operates from 420 seconds after 300 seconds when the fire source disappears. The temperature within the space tends to be similar to that of Figure 6 until 420 seconds but drops close to the outdoor temperature of $20^{\circ} \mathrm{C}$ in all opening height conditions due to the action of the smoke exhaust fan after 450 seconds.

Figure 8 shows smoke density contours on center plane with time for Case 1 where the height of the opening is $0.5 \mathrm{~m}$, and the smoke exhaust fan does not operate when a fire breaks out. Figure 8 (a) shows the smoke density contours in 200 seconds after the fire, which is a stage where the fire grows, when the smoke density at the top is about $4.0 \times 10^{-4} \mathrm{~kg} / \mathrm{m}^{3}$. Figure 8 (b) shows the smoke density contours in 100 seconds after the fire disappears when 300 seconds pass. The temperature showed a significant drop at 400 seconds, rather than at 300 seconds when the fire was almost extinguished, but the value of smoke density remains high in the entire upper space even at 400 seconds. And as in Figure 8 (c), which shows the smoke density contours in 600 seconds after the fire, the smoke density in the space still shows a high value in 300 seconds after the fire is extinguished. This finding suggests that the smoke generated from the fire cannot be discharged to the outside after the passage of time in the condition where the height of the opening is $0.5 \mathrm{~m}$.

Figure 9 shows smoke density contours on center plane at 600 seconds after the fire for fan-off condition where the height of the opening changes from 1.0 to $2.0 \mathrm{~m}$. Figure 9(a) shows the smoke density contours in the case where the opening height is $1.0 \mathrm{~m}$. Figure 9 (b) shows the result obtained from the case where the opening height is $1.5 \mathrm{~m}$, and Figure $9(\mathrm{c})$ shows the result from the case where the opening height is $2.0 \mathrm{~m}$. As shown in the figure, the smoke density contours is considerably high in the case where the opening height is $1.0 \mathrm{~m}$. However, as the height of the opening increases from $1.5 \mathrm{~m}$ to $2.0 \mathrm{~m}$, the amount 
of smoke discharged to the outside increases, and the smoke density within the space drops sharply. These results show that if the height of the opening increases, the amount of smoke discharged to the outside increases, and the smoke density in the space decreases.

Figure 10 shows smoke density contours on center plane with time for Case 5 where the opening height is $0.5 \mathrm{~m}$ when the smoke exhaust fan operates from 420 seconds after the fire source disappears at 300 seconds. Figure 10(a) shows the smoke density contours at 500 seconds after the fire occurs. As shown in the figure, as the smoke exhaust fan operates, a considerable amount of smoke is discharged toward the smoke exhaust fan, and the smoke density within the space becomes lower. Figure 10(b) shows the smoke density contours at 600 seconds after the fire occurs. It can be seen that all of the generated smoke is discharged, and the smoke density within the space is almost zero. These results are in contrast to the results of analysis on the conditions of the same opening height without operation of the smoke exhaust fan and show that the smoke is being discharged well by the smoke exhaust fan.

Figure 11 shows CO density contours on center plane at 600 seconds after the fire occurs in the condition where the height of the opening is $0.5 \mathrm{~m}$. Figure 11(a) shows the CO density contours for the condition where the smoke exhaust fan does not operate, and the smoke density within the space still shows a high value even at 300 seconds after the fire is extinguished. Figure 11(b) shows the analysis results for fan operating condition, and the generated $\mathrm{CO}$ is completely discharged, and the CO density within the space is almost zero.

Figure 12 shows smoke density variations over time with the height of opening at the monitoring point of $1 \mathrm{~m}$ in the lower part for fan-off condition. As shown in the figure, the smoke density at the monitoring point continues to rise up to 300 seconds when the fire source is present. After 300 seconds when the fire source disappears, the smoke density at the monitoring point does not drop significantly under the condition where the height of the opening is less than 1.0 $\mathrm{m}$, which suggests that the smoke is not discharged properly. On the other hand, the smoke is smoothly discharged to the opening, and the smoke density at the monitoring point is greatly reduced under the condition where the opening height is more than $1.5 \mathrm{~m}$.

Figure 13 shows smoke density variations over time with height of opening at the monitoring point of $1 \mathrm{~m}$ in the lower part when the smoke exhaust fan operates from 420 seconds after the fire source disappears at 300 seconds. The smoke density tends to be almost similar to that of Figure 12 until 420 seconds but drops close to zero as the smoke density within the space decreases rapidly in all opening conditions as the smoke is discharged to the outside due to the action of the smoke exhaust fan after 450 seconds.

Figure 14 and Figure 15 show CO density variations over time with the height of opening at the monitoring point of $1 \mathrm{~m}$ in the lower part for fan-off and fan-on conditions, respectively. The analysis model suggests that the production rate of $\mathrm{CO}$ is smaller than the smoke generation rate, and thus the den- 
sity value of $\mathrm{CO}$ within the space is lower than the density value of the smoke. As shown in the figure, the smoke density at the monitoring point is greatly reduced as $\mathrm{CO}$ is smoothly discharged when the smoke exhaust fan operates as in the case of the smoke density.

\section{Conclusions}

In this study, the numerical model of the portable smoke exhaust fan was derived from the building in which a fire occurred, and the analysis on the smoke and toxic gas exhaust effects was performed. Based on the results, the following conclusions were made.

1) The temperature at the monitoring point rises to more than $200^{\circ} \mathrm{C}$ up to 300 seconds when the fire source is present, and then decreases gradually after the temperature rapidly drops to less than $50^{\circ} \mathrm{C}$ up to 400 seconds after 300 seconds when the fire source disappears in a situation where the smoke exhaust fan does not operate.

2) The temperature within the space drops close to the outdoor temperature of $20^{\circ} \mathrm{C}$ in all opening height conditions due to the action of the smoke exhaust fan after 450 seconds in a situation where the smoke exhaust fan operates in 420 seconds after the fire source disappears at 300 seconds.

3) The smoke density within the space still shows a high value even in 300 seconds after the fire is extinguished under a condition where the height of the opening is $0.5 \mathrm{~m}$, and the smoke exhaust fan does not operate after a fire breaks out.

4) Under a condition where the height of the opening is less than $1.0 \mathrm{~m}$ after 300 seconds when the fire source disappears in a situation where the smoke exhaust fan does not operate, the smoke is not discharged properly, and thus the smoke density at the monitoring point does not drop significantly.

5) Meanwhile, even when the smoke exhaust fan does not operate, the smoke is smoothly discharged to the opening, and the smoke density at the monitoring point is greatly reduced under a condition where the opening height is more than $1.5 \mathrm{~m}$.

6) The smoke density drops close to zero as the smoke density within the space decreases rapidly in all opening height conditions as the smoke is discharged to the outside due to the action of the smoke exhaust fan after 450 seconds in a situation where the smoke exhaust fan operates from 420 seconds after the fire source disappears at 300 seconds.

\section{Acknowledgements}

This study was carried out with the support of the project, titled "Development of portable and rechargeable smoke exhaust fan for firefighting purpose (10058036)" managed by the Korea Evaluation Institute of Industrial Technology as a part of the industrial technology innovation program of the Ministry of Trade, Industry and Energy. We would thus like to extend our sincere appreciation to the said institutions. 


\section{References}

[1] Hall, J.R. (2009) Fatal Effects of Fire, NFPA.

[2] MPSS, NFSC 501 (2016) Fire Safety Standard of Smoke Control Facilities.

[3] BSI, BS EN 12101-3:2015 (2015) Smoke and Heat Control Systems-Part 3: Specification for Powered Smoke and Heat Control Ventilators (Fans).

[4] ASHRAE, ANSI/ASHRAE Standard 149-2013 (2013) Laboratory Methods of Testing Fans Used to Exhaust Smoke in Smoke Management Systems.

[5] Sheard, A.G. and Jones, N.M. (2012) Powered Smoke and Heat Exhaust Ventilators: The Impact of EN 12101-3 and ISO 21927-3. Tunnelling and Underground Space Technology, 28, 174-182.

[6] Jie, J., Kaiyuan, L., Wei, Z. and Ran, H. (2010) Experimental Investigation on Influence of Smoke Venting Velocity and Vent Height on Mechanical Smoke Exhaust Efficiency. Journal of Hazardous Materials, 177, 209-215.

[7] Yan, S.X., Wu, X.P., and Wang, D. (2011) Study of the Performance of Smoke Control under Non-Uniform Smoke Exhaust Velocity. Procedia Engineering, 11, 385 393.

[8] He, X.Z., Lu, S.X., Zhang, B.S., and Li, C.H. (2016) Effects of Supply-Exhaust Ratio on Smoke Exhaust Efficiency in a Large Machinery Space. Procedia Engineering, $135,469-475$.

[9] NIST (2016) Fire Dynamic Simulator User's Guide.

Submit or recommend next manuscript to SCIRP and we will provide best service for you:

Accepting pre-submission inquiries through Email, Facebook, LinkedIn, Twitter, etc. A wide selection of journals (inclusive of 9 subjects, more than 200 journals) Providing 24-hour high-quality service User-friendly online submission system Fair and swift peer-review system Efficient typesetting and proofreading procedure Display of the result of downloads and visits, as well as the number of cited articles Maximum dissemination of your research work

Submit your manuscript at: http://papersubmission.scirp.org/

Or contact ojfd@scirp.org 